\title{
DOE/PC/94217-- 16
}

DOE/MST-9505

\section{A STUDY OF \\ MULTISTAGE/MULTIFUNCTION COLUMN FOR FINE PARTICLE SEPARATION}

\section{QUARTERLY TECHNICAL PROGRESS REPORT}

(October 1, 1995 - December 31, 1995)

$\begin{array}{ll}\text { Principal Investigator: } & \text { Dr. Shiao-Hung Chiang } \\ \text { Project Officer: } & \text { Dr. Ralph W. Lai }\end{array}$

Work Performed under DOE Contract No. DE-PG22-94PC94217

(Award: \$200,000; Duration: July 8, 1994 - July 7, 1997 )

\author{
Submitted to
}

U.S. Department of Energy

Pittsburgh Energy Technology Center

Pittsburgh, PA 15236-0940

by

Chemical and Petroleum Engineering Department

University of Pittsburgh

Pittsburgh, PA 15261

January 20, 1996

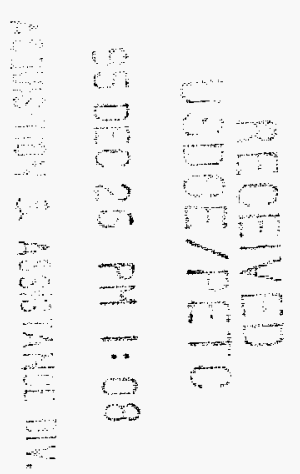




\subsection{INTRODUCTION}

The overall objective of the proposed research program is to explore the potential application of a new invention involving a multistage column equipped with vortex-inducing loopflow contactors (hereafter referred to as the multistage column) for fine coal cleaning process. The research work will identify the design parameters and their effects on the performance of the separation process. The results of this study will provide an engineering basis for further development of this technology in coal cleaning and in the general areas of fluid/particle separation.

In the last quarter, the bubble size measurements were carried out in the conventional column. Also, correlations were developed for results on gas holdup, bubble size and specific interfacial area ${ }^{[1]}$. In this quarter, we investigated the mixing and loop flow (circulation) behaviors around the contactor. Table 1.1, the project schedule, shows work accomplished to date.

Table 1.1 Project Schedule

\begin{tabular}{|c|c|c|c|c|c|c|c|c|c|c|c|c|c|}
\hline \multirow{2}{*}{ Tasks } & \multicolumn{3}{|c|}{1994} & \multicolumn{3}{|c|}{1995} & \multicolumn{3}{|c|}{1996} & \multicolumn{3}{|c|}{1997} & \multirow[b]{2}{*}{6} \\
\hline & 7 & 9 & 12 & 3 & 6 & 9 & 12 & 3 & 6 & 9 & 12 & 3 & \\
\hline 1. Project Planning & 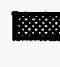 & & & & & & & & & & & & \\
\hline 2. Equipment & & & & 좄 & & & & & & & & & \\
\hline 3. Hydrodynamic $\mathrm{Te}$ & & & & x & & & 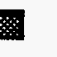 & & & & & & \\
\hline 4. Separation Tests & & & & & & & [ & & & & & & ב \\
\hline 5. Conventional Col & & & & & & & & & & & & & \\
\hline 6. Data Analysis & & & & & & & 5 & & & & & & \\
\hline 7. Reports & & $\square$ & $\square$ & $\square$ & 중 & $\square$ & $\square$ & $\square$ & 网 & $\square$ & $\square$ & $\square$ & : \\
\hline
\end{tabular}




\subsection{TECHNICAL PROGRESS}

\subsection{Task 1: Project Planning}

This task was completed in September $1994^{[2]}$.

\subsection{Task 2: Equipment Design and Construction}

Task 2 was completed in March $1995^{[3]}$.

\subsection{Task 3: Hydrodynamic Tests}

The objective of this task is to pursue a basic understanding of the hydrodynamic behavior and to characterize the flow and mixing conditions in the multistage separation column.

In the last quarter, we completed the image analyses of the bubble sizes based on the test data. Also, we attempted to derive correlations of data on gas holdup, bubble size and specific interfacial area obtained from the three-stage column and conventional column. These results were reported in the last quarterly report ${ }^{[1]}$. In this quarter, we have completed the following subtasks:

1. The investigation of mixing behavior in the multistage column and conventional column:

a. Setting up and calibrate the conductivity meter and auxiliary devices;

b. Measurements of mixing time under various operating conditions.

2. The investigation of circulation flow characteristics around the contactor:

a. Definition of the circulation velocity and development of a measurement procedure;

b. Measurements of the circulation velocity around the contactor. 


\subsubsection{Mixing Behavior}

In a separation column, adequate mixing environment is the key for creating a proper flow pattern required for the intimate contacts among the constituents. However, excessive agitation can also cause backmixing and entrainment, resulting in poor process performance. Thus, an agitated column should be designed in such a manner to promote mixing while minimize the adverse hydrodynamic effects. Further, the mixing condition is an important criterion for the scale up of a separation column. For these purposes, a study was performed to delineate the mixing characteristics in the multistage column.

\subsubsection{Principles}

The liquid-phase mixing time and circulation velocity were measured using tracer response techniques. When a tracer is introduced at the injection point, a dampened sinusoidal response as depicted in Figure 2.3.1a would be detected at a selected down stream location. The time interval between adjacent peaks on the recorder output is taken as the circulation time, $t_{c}$. As defined, the mean liquid circulation velocity, $\mathrm{u}_{\mathrm{LC}}$ is calculated based on the following expression:

$$
u_{L C}=\frac{H_{c}}{t_{c}}
$$

where $\mathrm{H}_{\mathrm{c}}$ is the distance between the tracer injection port and the detecting probe; $t_{c}$ is the circulation time.

Since the dispersion in the multistage column is faster than that in air lift loop columns with long draft tubes, the dampened response curve is as depicted in Figure 2.3.1b. The mean liquid 
circulation time can also be measured by two probes. In this case, $t_{c}$ in Eq. 2.3 .1 should be replaced by $t_{R}$, which represents the time interval between two responses.

The mixing characteristics is represented by the "liquid-phase mixing time". The liquidphase mixing time is defined as the time interval from the commencement of a concentration disturbance induced by tracer injection to the time at which the concentration deviates within $5 \%$ of the tracer concentration response under the complete mixing condition (see Figure 2.3.1a).

In this study, the conductivity technique was used to determine the mixing time. The conductivity measurements were performed using an Analog Conductivity Meter (Cole-Parmer 19100) equipped with a Flat-Bed Recorder. Two probes were used: one probe was located at the top of the contactor and the other at the bottom of the same contactor. The distance between the two probes was constant. Saturated potassium chloride $(\mathrm{KCl})$ was used as the tracer and was injected through the port at the location of the top probe to increase the conductivity of the tap water. A response for a conductivity change would be detected by the bottom probe. The mixing time and the circulation time could be determined from the output response curve obtained from the Flat-bed Recorder. In all runs, care was exercised in keeping the amount of $\mathrm{KCl}$, the manner of tracer addition and the end point of homogeneity the same, as they would influence the measured mixing time and thus the comparison of the results.

\subsubsection{Experimental Results and Discussion}

As shown in Table 2.3.1 the data for pure water indicate that the effects of agitation $(N)$ and superficial gas velocity (SGV) on the mixing time are significant. The mixing time decreases 


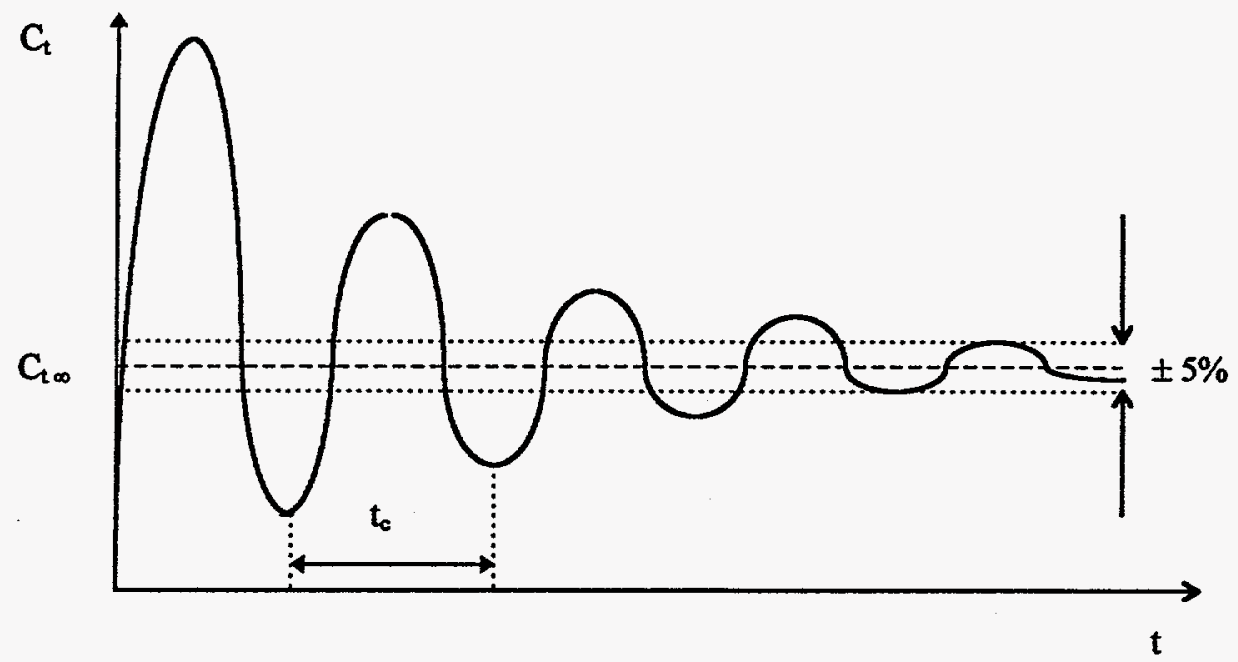

(a)

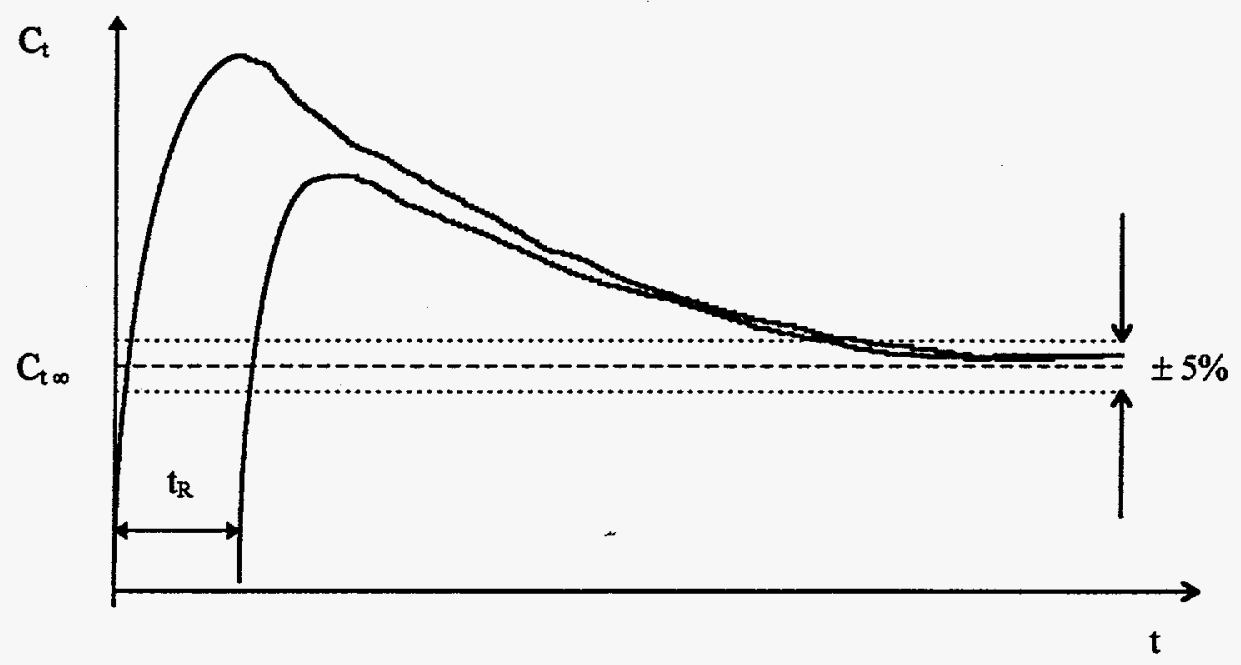

(b)

Figure 2.3.1 Response Curve for Pulse Input of Tracer

(a) Loop Reactor with Long Draft Tubes

(b) The Multistage Column

$C_{t}$ - tracer concentration response at time $t$;

$\mathrm{C}_{\text {too }}$ - tracer concentration response under the complete mixing condition. 
as $\mathrm{N}$ and SGV increase. A comparison of the mixing time between the multistage column and the conventional agitated column is presented in Table 2.3.2. The results show that the multistage column provides a more effective mixing than the conventional agitated column. Moreover, the data demonstrate that the effect of $\mathrm{N}$ on mixing time is more significant in the multistage column than in the conventional agitated column. This is because in the multistage column the vortexinducing contactor creates a strong loop flow pattern which does not exist in the conventional agitated column. Due to the multistage arrangement, the mixing within each stage does not result in inter-mixing among stages. Therefore, backmixing along the column is minimized.

Table 2.3.1 Mixing Time Data Obtained from Multistage Column

\begin{tabular}{|c|c|c|c|c|}
\hline \multirow{2}{*}{$\mathrm{NGV}, \mathrm{m} / \mathrm{s}$} & \multicolumn{4}{|c|}{ Mixing Time, seconds } \\
\cline { 2 - 5 } & 0.01 & 0.03 & 0.05 & 0.09 \\
\hline 14.67 & 100 & 67.5 & 52.5 & 52.5 \\
30.00 & 70.0 & 57.5 & 50.0 & 42.5 \\
45.00 & 62.5 & 52.5 & 45.0 & 35.0 \\
\hline
\end{tabular}


Table 2.3.2 Comparison of Mixing Time between Multistage Column and

Conventional Agitated Column (SGV $=0.09 \mathrm{~m} / \mathrm{s}$ )

\begin{tabular}{|l|cccc|}
\hline \multicolumn{5}{|c|}{ Mixing Time, seconds } \\
\hline Agitation Speed, Hz & 0.00 & 14.67 & 30.00 & 45.00 \\
\hline Multistage Column & 52.5 & 42.5 & 35.0 & 27.5 \\
Conventional Agitated Column & 52.5 & 45.0 & 42.5 & 40.0 \\
\hline
\end{tabular}

The effect of the frother (methyl isobutyl carbinol, MIBC) dosage on mixing time is quite different from those of the $\mathrm{N}$ and SGV. The experimental data show that under $\mathrm{N}=45 \mathrm{~Hz}$ and SVG $=0.09 \mathrm{~m} / \mathrm{s}$ an increase in MIBC dosage from $0 \mathrm{mg} / \mathrm{L}$ to $25 \mathrm{mg} / \mathrm{L}$ causes an increase in the mixing time from 27.5 seconds to 70 seconds. Similar trends were also observed under other operating conditions. This phenomenon can be attributed to the fact that an increase in MIBC dosage results in a less turbulent flow pattern around the contactor because of the presence of smaller and more stable gas bubbles.

Unlike the mixing time, the liquid circulation in a multistage column appeared to be less sensitive to operating conditions. As listed in Table 2.3.3, when a small amount of MIBC is added, the circulation velocity remains almost constant around a typical value of $0.12 \mathrm{~m} / \mathrm{s}$. Two opposing effects accounted for the occurrence of this phenomenon. On the one hand, the increase of $\mathrm{N}$ tends to increase the pressure difference between the riser and downcomer, thus results in an increase of the circulation velocity. On the other hand, the increase of $\mathrm{N}$ causes the increase in gas holdup in annular region. This would lower the bulk density difference and thus reduce the 
circulating velocity. Therefore, under the compensating action of these two factors the circulation velocity does not change significantly with the operating variables.

Table 2.3.3 Circulation Velocity in the Multistage Column

\begin{tabular}{|c|c|c|c|c|c|}
\hline $\begin{array}{c}\text { Agitation Speed } \\
(\mathrm{Hz})\end{array}$ & \multicolumn{5}{|c|}{ Circulation Velocity $\left(10^{-2} \mathrm{~m} / \mathrm{s}\right)$} \\
\cline { 2 - 6 } & $\begin{array}{c}\text { MIBC } \\
0 \mathrm{ppm}\end{array}$ & $\begin{array}{c}\text { MIBC } \\
7 \mathrm{ppm}\end{array}$ & $\begin{array}{c}\text { MIBC } \\
15 \mathrm{ppm}\end{array}$ & $\begin{array}{c}\text { MIIBC } \\
20 \mathrm{ppm}\end{array}$ & $\begin{array}{c}\text { MIBC } \\
25 \mathrm{ppm}\end{array}$ \\
\hline 30 & 12.1 & 15.1 & 13.4 & 12.1 & 12.1 \\
\hline 45 & 20.2 & 15.1 & 13.4 & 13.4 & 11.0 \\
\hline
\end{tabular}

In summary, the experimental investigation of mixing behavior shows that the multistage column design provides a technical means to overcome the shortcomings in the conventional columns. For example, one of the general understanding about bubble column is that the increased gas holdup will sacrifice the mixing performance. However, in the multistage column, although the gas holdup was higher than that in the conventional column, the mixing time is comparable to or even shorter than that in the conventional column. This improvement is directly related to the special design of the multiple vortex-inducing contactors.

\subsection{Task 4: Separation Tests}

This task will be initiated in January 1996.

\subsection{Task 5: Conventional Column Tests}

In the previous quarter, we conducted the study of the gas holdup, bubble size and specific interfacial area in the conventional flotation column. The results were reported in the last 
quarterly report $^{[1]}$. In this quarter, experiments similar to those for Task 3 were carried out to study the liquid mixing and circulation behavior in the conventional flotation column.

\subsection{Task 6: Data Analysis}

For engineering design and scale-up, an understanding of the hydrodynamic behavior of the multistage column is required. Gas holdup and specific interfacial area are two key parameters for evaluating the performance of the multistage column. In the last quarter, data for the gas holdup, bubble size and specific interfacial area ${ }^{[4]}$ were analyzed in terms of three key operating parameters: SGV, $\mathrm{N}$ and frother dosage. Three second-order polynomial equations ${ }^{[1,5]}$ were presented and agree very well with the corresponding experimental data. In this quarter, the data for mixing time and circulation velocity data were analyzed.

\subsection{Summary}

During the past year, experimental measurements of the overall gas holdup, gas bubble size and specific interfacial area were conducted to evaluate the effects of various operating parameters on the hydrodynamic behavior of the multistage column. The mathematical expressions developed using the multi-parameter regression method provided adequate correlation for the experimental data. In this quarter, we continued to study the hydrodynamic behavior in terms of mixing time and circulation flow pattern. In summary, the following points are noted:

1. The experimental investigation of the liquid-phase mixing behavior in the multistage column shows that the design concept of the multistage column equipped with vortex- 
inducing contactors is expected to provide an improved performance as compared to the conventional column.

2. The superficial gas velocity, the agitation speed and the froth dosage are three operating parameters affecting liquid-phase mixing time.

3. The liquid circulation in a multistage column appears to be less sensitive to changes in operating conditions than in the conventional column.

\subsection{WORK FORECAST}

In the next two quarters, work under Task 4: Separation Tests will be initiated, which include the following:

- Fine coal cleaning tests;

- Comparison of the beneficiation performance between the multistage column and conventional column in terms of :

- separation rate;

- heating value recovery;

- ash rejection and

- pyritic sulfur rejection. 


\subsection{REFERENCES}

1. "A Study of Multistage/Multifunction Column for Fine Particle Separation", Quarterly Technical Progress Report, (July 1, 1995 - September 30, 1995), Chemical \& Petroleum Engineering Department, University of Pittsburgh, Submitted to U.S. Department of Energy, PETC, January 20, 1995.

2. “A Study of Multistage/Multifunction Column for Fine Particle Separation", Quarterly Technical Progress Report, (July 1, 1994 - September 30, 1994), Chemical \& Petroleum Engineering Department, University of Pittsburgh, Submitted to U.S. Department of Energy, PETC, February 2, 1995.

3. "A Study of Multistage/Multifunction Column for Fine Particle Separation", Quarterly Technical Progress Report, (October 1 - December 31, 1994), Chemical \& Petroleum Engineering Department, University of Pittsburgh, Submitted to U.S. Department of Energy, PETC, April 20, 1995.

4. "A Study of Multistage/Multifunction Column for Fine Particle Separation", Quarterly Technical Progress Report, (April 1, 1995 - June 30, 1995), Chemical \& Petroleum Engineering Department, University of Pittsburgh, Submitted to U.S. Department of Energy, PETC, July 20, 1995.

5. He, Da-Xin, "A Computer Program: Non-Linear Multi-Parameter Regression," (unpublished), September, 1995. 


\subsection{APPENDIX}

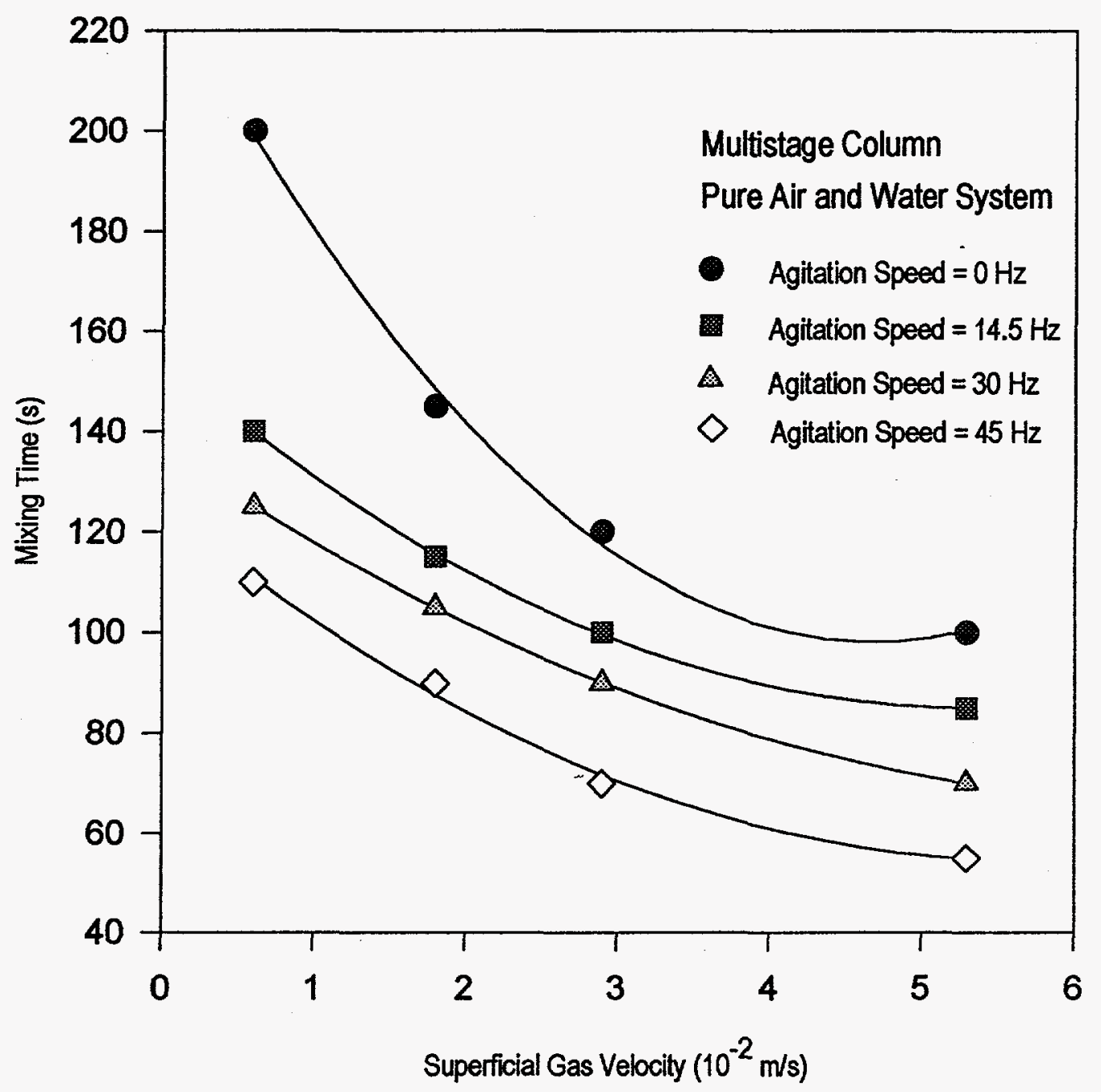

Figure 1 Effect of Superficial Gas Velocity on Mixing Time 


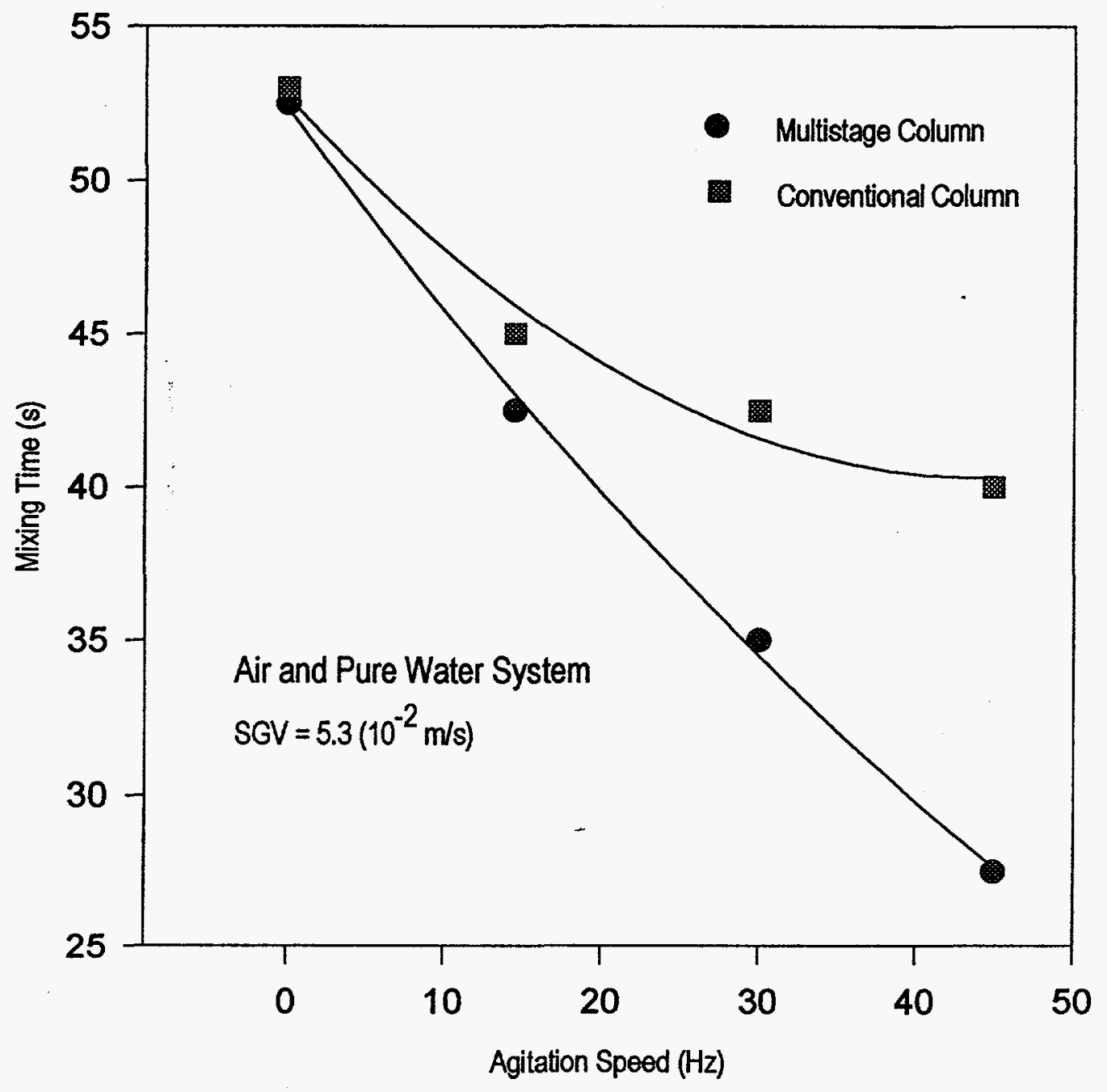

Figure 2 Effect of Agitation Speed on Mixing Time 


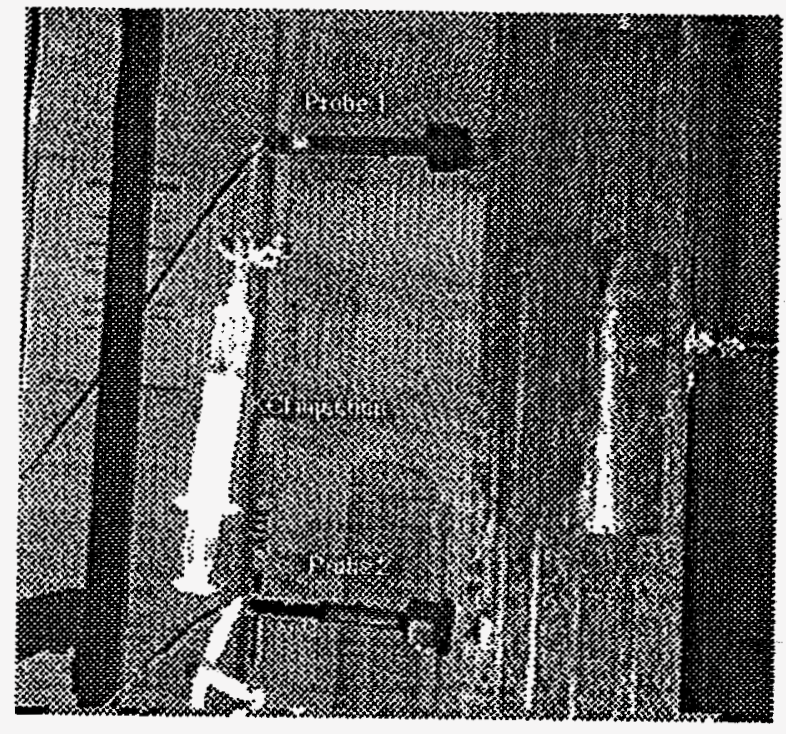

\section{Figure 3 Conductivity Probes and $\mathrm{KCl}$ injector}

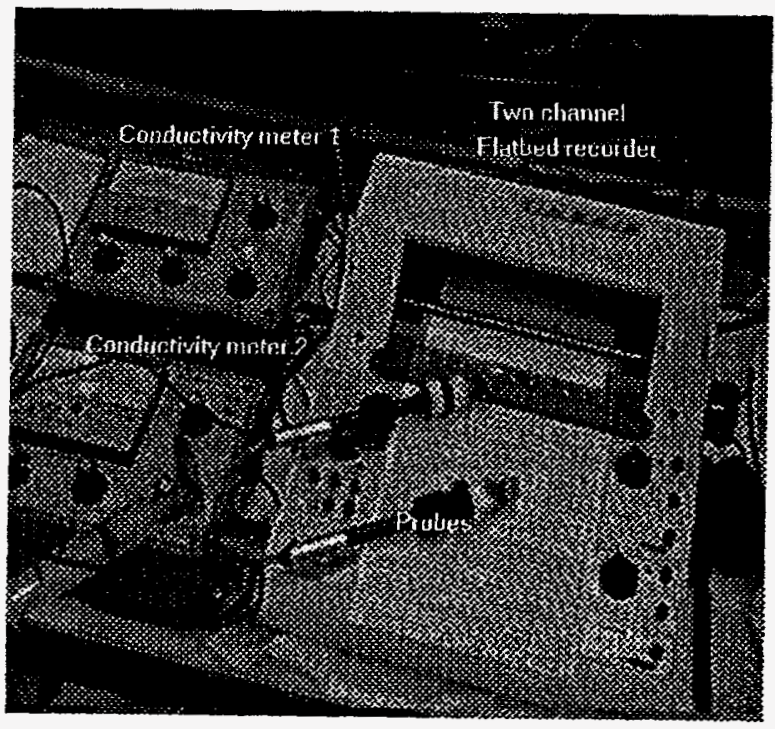

\section{Figure 4 Analogy Conductivity Meters and Flat-Bed Recorder}

\section{DISCLAIMER}

This report was prepared as an account of work sponsored by an agency of the United States Government. Neither the United States Government nor any agency thereof, nor any of their employees, makes any warranty, express or implied, or assumes any legal liability or responsibility for the accuracy, completeness, or usefulness of any information, apparatus, product, or process disclosed, or represents that its use would not infringe privately owned rights. Reference herein to any specific commercial product, process, or service by trade name, trademark, manufacturer, or otherwise does not necessarily constitute or imply its endorsement, recommendation, or favoring by the United States Government or any agency thereof. The views and opinions of authors expressed herein do not necessarily state or reflect those of the United States Government or any agency thereof. 